\title{
Serial survey shows community intervention may contribute to increase in knowledge of Tuberculosis in 30 districts of India
}

Badri Thapa, Banuru Muralidhara Prasad*, Sarabjit S. Chadha and Jamie Tonsing

\begin{abstract}
Background: Correct knowledge about Tuberculosis (TB) is essential for appropriate healthcare seeking behaviour and to accessing diagnosis and treatment services timely. There are several factors influencing knowledge about TB. The present study was conducted to assess the change in community knowledge of Tuberculosis (TB) and its association with respondent's socio-demographic characteristics in two serial knowledge-attitude-practice surveys.

Methods: Community level interventions including community meetings with youth groups, village health committees and self-help groups and through mass media activities were undertaken to create awareness and knowledge about TB and service availability. Increase in knowledge on TB and its association with respondent's socio-demographic characteristics was assessed by two serial KAP surveys in 2010-2011 (baseline) and 2012-2013 (midline) in 30 districts of India. Correct knowledge of TB was assessed by using lead questions and scores were assigned. The composite score was dichotomized into two groups (score 0-6, poor TB knowledge and score 7-13, good TB knowledge).
\end{abstract}

Results: In baseline and midline survey, 4562 and 4808 individuals were interviewed. The correct knowledge about TB; cough $\geq 2$ weeks, transmission through air, 6-8 months treatment duration, and free treatment increased by $7 \%$ ( $p$-value $<0.05), 11 \%$ ( $p$-value <0.05), $2 \%$ ( $p$-value $<0.05)$, and $8 \%$ ( $p$-value $<0.05)$ in midline compared to baseline, respectively. The knowledge on sputum smear test for diagnosis of TB was $66 \%$ in both surveys while knowledge on availability of free treatment and that TB is curable disease decreased by $5 \%$ and $2 \%$ in midline $(p-0.001)$, compared to baseline, respectively. The mean score for correct knowledge about TB increased from $60 \%$ in baseline to $71 \%$ in midline which is a $11 \%$ increase ( $p$-value $<0.001)$. The misconception regarding on transmission of TB by- sharing of food and clothes and handshake persisted in midline. Respondents residing in northern $(\mathrm{OR}, 2.2,95 \% \mathrm{Cl}, 1.7-2.6)$ and western districts $(\mathrm{OR}, 3.4,95 \% \mathrm{Cl}, 2.7-4.1)$ of India and age groups- 25-34 years $(\mathrm{OR}, 1.3 ; 95 \% \mathrm{Cl}, 1.1-1.6)$ and $45-44$ years $(\mathrm{OR}, 1.4 ; 95 \% \mathrm{Cl}, 1.1-1.7)$ - were independently associated with good TB knowledge.

Conclusions: The knowledge about TB has increased over a period of 2 years and this may be attributable to the community intervention in 30 districts of India. The study offers valuable lesson for designing TB related awareness programmes in India and in other high burden countries.

Keywords: Tuberculosis, Knowledge, Attitude and practice (KAP), India, Community level

\footnotetext{
* Correspondence: bmprasad@theunion.org; drprasadbm@gmail.com International Union Against Tuberculosis and Lung Disease, C-6, Qutub Institutional Area, New Delhi 110016, India
}

(c) The Author(s). 2016 Open Access This article is distributed under the terms of the Creative Commons Attribution 4.0 International License (http://creativecommons.org/licenses/by/4.0/), which permits unrestricted use, distribution, and reproduction in any medium, provided you give appropriate credit to the original author(s) and the source, provide a link to the Creative Commons license, and indicate if changes were made. The Creative Commons Public Domain Dedication waiver (http://creativecommons.org/publicdomain/zero/1.0/) applies to the data made available in this article, unless otherwise stated. 


\section{Background}

Globally, India is one of the high-burden Tuberculosis (TB) countries contributing to $24 \%$ of estimated new cases and $20 \%$ of TB related deaths in 2013 [1]. The notification rate of all forms of TB (new and relapse) and bacteriologically confirmed cases were 99 and 50 respectively per 100,000 population in 2013 and the notification rate of all TB cases was 113 per 100,000 population. Despite efforts to increase TB case detection, it is estimated that nearly a million cases are being missed in India every year [2]. The missing million could be those who remained un-diagnosed, and not treated for TB or not notified to the programme [3].

In India, private health care facilities are the first and preferred point of contact for $57 \%$ of urban and $48 \%$ of rural population [4]. Almost $50 \%$ of cases detected in private sector are not reported to the programme which is also one of the contributing factor to missing million cases [5]. The lack of awareness and knowledge about symptoms, accurate diagnosis, and treatment of $\mathrm{TB}$ hinders the access to free $\mathrm{TB}$ services [6]. Deep-rooted stigma and misconceptions to TB also contribute to delay in health care seeking behaviour and prevented people from accessing services [7]. Efforts made by National TB Program (NTP) to establish community level patient centric directlyobserved-treatment (DOT) providers was shadowed by stigma and misconceptions towards TB. In addition programme had limited success in engaging local service providers, and community members, to educate people on TB and its free services [8].

Community engagement was on priority and The Global Fund supported TB project -'Axshya' (means free of TB in Indian language) (IDA-910-G17-T) was implemented since 2010 to engage civil society to create awareness about TB and the availability of services under NTP $[9,10]$. The project activities are primarily aimed at creating awareness and knowledge about TB (symptoms, diagnosis, treatment and availability of free services) among marginalised and vulnerable communities with limited access to TB services in both rural and urban areas. During the first year of project implementation, 2010-11 a baseline survey was conducted to assess the knowledge, attitude and practices (KAP) among key community groups about TB. In the third year of the project 2012-13, a midline survey was conducted to assess the change in KAP and provide evidence-based guidance to identify gaps in implementation and improvise the strategies $[9,10]$. The present study analysed the secondary data pertaining to general population from the two serial surveys to assess the knowledge of TB and its association with respondent's socio-demographic characteristics.

\section{Methods}

\section{Study settings}

The community level intervention activities of project 'Axshya' are implemented in 374 districts across 25 states of India [11]. Project districts were selected based on a composite indicators; those districts having higher number of marginalized and vulnerable population, low TB case detection and limited access to TB services. The interventions include activities to create awareness and knowledge about TB and availability of its free services (symptoms, place of free diagnosis and treatment) through community meetings with village health committees, and various community groups including, youth groups, selfhelp groups, and village head groups. Information about TB was also disseminated through mid-media activities including; community radio, wall painting and street plays. One of the key activities implemented from April 2013 onwards was house-to-house visits by trained community volunteers to inform household members about TB, and to identify presumptive TB patients with cough $\geq 2$ weeks and link them with TB services for diagnosis and treatment. From, April 2013 till March 2014, the project has reached five million households and has contributed directly to diagnosis of more than 14,000 smear positive TB patients [12].

\section{Survey design, sample size, sampling technique and study participants}

In 2010-11 and 2012-13, baseline and midline crosssectional KAP surveys about TB were conducted among general population (excluding TB patients), opinion leaders, non-governmental organizations, health care service providers and TB patients in 30 of the 374 Project Axshya districts $[9,11]$. The survey districts were selected through a three staged stratified cluster sampling technique. First, 374 districts were stratified into four zones (north, south, east and west). Of these, 30 representative districts were selected based on population proportion to size (PPS) sampling method. Second, primary sampling units (PSUs)-10 rural and urban villages- were selected in each district using PPS. Third, in each PSU, household listing was carried out which involved assigning numbers to each residential structure, recording address and location of these structures, listing the numbers of individuals in the households, and identification of the head of the household. Then 15 individual respondents (age $>18$ years, men: women ratio of $1: 1)$ were selected based on the systematic sampling method. To have a statistical power of $80 \%$ to ascertain $2 \%$ or more change at the midline in comparison to baseline, a sample size of 4500 respondents from general population was required. Therefore, sample size with additional $10 \%$ non-response rate was used. The sample size in both surveys was calculated using the same methods $[9,11]$. 


\section{Data collection, entry and analysis}

The study was implemented by The Union, South-East Asia Regional Office, New Delhi, India with assistance from field investigators of the social research organization GfK MODE. The primary sampling units (PSUs) were visited by the trained field investigators during the survey period. The survey included a semi-quantitative questionnaire developed in eight local languages to collect the data and was piloted before being administered to the general population. This semi-structured questionnaire included demographic data on age, sex, settlement (urban/rural), monthly household income (in Indian rupees), literacy status (an illiterate was considered as a person who cannot read and write in any language), and zones. The data on heard of TB, source and preferred source of TB information, knowledge and misconceptions on TB symptoms; mode of transmission, diagnosis, and duration of treatment, 'completely curable' and directly observed treatment short course (DOTS) were collected. Data collected were entered into Epi-data (version 2.2.1) and exported into Statistical Package for the Social Sciences (SPSS) version 16 for further analysis. Categorical variables were summarized using proportions and compared using Chi-square test, comparison of mean were done by Student's t-test and Analysis of variance (ANOVA) and $p$-value of less than 0.05 was considered statistically significant.

For assessing the predictors of good knowledge, a univariate and multivariate logistic regression analysis was performed. The correct knowledge of TB among the study participants was assessed using 13 questions on 'cough $\geq 2$ weeks', 'coughing blood,' 'chest pain', 'fever', 'weight loss' and, 'night sweats' and 'loss of appetite' as symptoms of TB, 'air' as a mode of transmission of TB, 'sputum smear test' as a diagnostic tool, TB is 'completely curable, duration of treatment of ' $6-8$ months or more', knows as DOTS and 'DOTS is free'. Each correct answer was scored " 1 " and incorrect answer (including don't know) was scored "0". The cut off score for correct knowledge was taken at more than $50 \%$ i.e., more than 6 out of 13. The composite score was dichotomized into two groups (score 0-6, poor TB knowledge and score 7-13, good TB knowledge).

\section{Results}

\section{Respondents and heard of TB}

Baseline and midline surveys interviewed 4562 and 4804 individuals, respectively (Table 1). Sex and geographical distribution of the respondents were not statistically significant different between the surveys $(p>0.05)$. There were subtle significant differences in age groups, settlements, education and income level between two surveys $(p<0.001)$ but overall the demographic data were quite similar in both surveys. Of those interviewed, $3822(84 \%)$ in baseline and $4211(88 \%)$ in midline had heard of TB, a $4 \%$ increase in comparison to baseline survey $(p<0.001)$ (Table 2$)$.

\section{Correct knowledge and misconception on TB}

The knowledge on common symptoms of TB (except chest pain) increased in midline in comparison to the baseline (Table 2). The correct knowledge on the most common symptom of TB- cough $\geq 2$ weeks increased from $74 \%$ in baseline to $81 \%$ in midline, a $7 \%$ increase ( $p$-value $<0.05)$. Similar significant increase in knowledge were noted in midline survey for, other common symptoms, coughing of blood (45\% vs $55 \%$ ), weight loss (17\% vs $21 \%$ ) and loss of appetite (9 \% vs $16 \%$ ) in comparison to baseline ( $p$-value $<0.05$ ).

The correct knowledge about mode of transmission of TB through air increased from 60 to $71 \%$ in the midline, a $11 \%$ increase ( $p$-value <0.001). The misconception that TB could be transmitted through sharing of food and clothes showed a marginal increase in midline $(37 \%$ and $21 \%$ ) compared to the baseline (31\% and $14 \%)$, respectively ( $p$-value $<0.05$ ). However, the misconception on transmission through handshake reduced from $18 \%$ in baseline to $12 \%$ in midline ( $p$-value <0.001). The knowledge that diagnosis of $\mathrm{TB}$ is done by sputum smear examination showed no change in both surveys (66\%, $p=1.00)$. The misconceptions on the diagnostic tests (chest X-ray and others blood and tuberculin test) significantly reduced in midline in comparison to the baseline $(p-<0.001)$.

The response to TB is "completely curable", decreased to $5 \%$ in midline. The correct knowledge about treatment duration of TB ( $\geq 6$ months) increased from $54 \%$ in baseline to $66 \%$ in midline ( $p$-value <0.001). The knowledge on DOTS decreased by $2 \%$ in midline in comparison to baseline ( $p$-value $<0.05)$. Among those who were aware of DOTS, $88 \%$ knew it was available free of cost in midline, compared to $80 \%$ in the baseline ( $p$-value $<0.05)$. In all knowledge areas, individuals who said "don't know" declined in the midline.

The mean score for correct knowledge was $5.1 \pm$ 2.3 in baseline which increased to $5.7 \pm 2.2$ in midline $(p$-value $<0.05)$ with $12 \%$ increase. The mean score changed slightly for all characteristics in midline in comparison to baseline except for respondents residing in urban areas (Table 3).

\section{Source and preferred source of TB related information}

The most common sources of TB related information were television $(37 \%, 1657)$ and hospital doctors $(37 \%$, 1665) in baseline and interpersonal communication $(58 \%)$ in midline (Table 4). The source of TB related information through all means in midline increased in comparison to baseline. Strikingly, information through interpersonal communication (IPC) changed from $27 \%$ 
Table 1 Socio-demographic characteristics of survey respondents in baseline (2010-2011) and midline (2012-2013) survey in 30 districts in India

\begin{tabular}{|c|c|c|c|c|c|c|c|}
\hline \multirow[t]{3}{*}{ Characteristics } & \multicolumn{2}{|c|}{ Baseline survey } & \multicolumn{2}{|c|}{ Midline survey } & \multirow{2}{*}{$\begin{array}{l}\text { Total } \\
\text { Respondents }\end{array}$} & \multirow[b]{3}{*}{$\%$} & \multirow[b]{3}{*}{$p$-value } \\
\hline & \multicolumn{2}{|c|}{ Respondents } & \multicolumn{2}{|c|}{ Respondents } & & & \\
\hline & $n$ & $\%$ & $n$ & $\%$ & $n$ & & \\
\hline Total & 4562 & & 4804 & & 9366 & & \\
\hline \multicolumn{8}{|l|}{ Sex } \\
\hline Women & 2242 & 49 & 2396 & 50 & 4638 & 50 & 0.29 \\
\hline Men & 2320 & 51 & 2408 & 50 & 4728 & 50 & \\
\hline \multicolumn{8}{|l|}{ Age (years) } \\
\hline $18-24$ & 692 & 15 & 686 & 17 & 1378 & 14 & $<0.001$ \\
\hline $25-34$ & 1266 & 28 & 1272 & 31 & 2538 & 26 & \\
\hline $35-44$ & 1427 & 31 & 1238 & 30 & 2665 & 26 & \\
\hline $45-54$ & 957 & 21 & 865 & 21 & 1822 & 18 & \\
\hline$>55$ & 220 & 5 & 743 & 18 & 963 & 15 & \\
\hline \multicolumn{8}{|l|}{ Settlement } \\
\hline Rural & 3388 & 74 & 3360 & 70 & 6748 & 72 & $<0.001$ \\
\hline Urban & 1174 & 26 & 1440 & 30 & 2614 & 28 & \\
\hline \multicolumn{8}{|l|}{ Education $^{a}$} \\
\hline Illiterate & 1394 & 31 & 1110 & 23 & 2504 & 27 & $<0.001$ \\
\hline Literate & 3168 & 69 & 3668 & 77 & 6836 & 73 & \\
\hline \multicolumn{8}{|l|}{ Income } \\
\hline$<4000$ & 2875 & 63 & 2165 & 45 & 5040 & 54 & $<0.001$ \\
\hline$>4001$ & 1580 & 35 & 2422 & 50 & 4002 & 43 & \\
\hline Don't know & 107 & 2 & 217 & 5 & 324 & 3 & \\
\hline \multicolumn{8}{|l|}{ Zones } \\
\hline North & 1067 & 23 & 1123 & 23 & 2190 & 23 & 0.98 \\
\hline East & 1234 & 27 & 1279 & 27 & 2513 & 27 & \\
\hline West & 1202 & 26 & 1280 & 27 & 2482 & 27 & \\
\hline South & 1059 & 23 & 1122 & 23 & 2181 & 23 & \\
\hline
\end{tabular}

${ }^{a}$ Education information not available for 26 respondents in midline

in baseline to $58 \%$ in midline with $115 \%$ increase ( $p$-value, <0.001). Television was also preferred source of information in the midline which increased from 44 to $61 \%(p$-value $<0.05)$.

\section{Association of TB knowledge with respondents background characteristics}

Univariate logistic regression analysis was carried and those respondent's background socio-characteristics with $p$-value $<0.05$ were included into the multiple logistic regression analysis to determine the association of respondent's background characteristics on the outcome measures (good knowledge about TB before [baseline survey] and during [midline survey] the project interventions). The age groups-25-34 years (OR, 1.3), and 35-44 years (OR, 1.4), and respondents residing in North (OR, 2.2), East (OR, 2.1) and West (OR, 3.4) were more likely to have correct TB knowledge in midline than baseline survey ( $p$-value $<0.05$ ) (Table 5). People with higher income group $>4000$ Indian Rupees per month had better knowledge about tuberculosis $(p-<0.001)$. The correct TB knowledge was not associated with rural (OR, 0.4 vs 0.8 ) and illiterate (OR 0.4 vs 0.5 ) groups in both surveys, the odds of having correct knowledge among these groups improved in the midline albeit at low level.

\section{Discussion}

The survey results show an increase in the knowledge and awareness of TB among the general population. The correct knowledge in areas like, symptoms, transmission, diagnosis, duration of treatment also considerably increased in the midline. The number of presumptive TB patients examined in the 374 project districts increased from 99,07,457 (2010-2011) to 10,257,051 (2012-2013), a $4 \%$ change $[13,14]$. This increase in correct knowledge and improved utilization of TB diagnostic services 
Table 2 Knowledge of Tuberculosis among respondents in baseline (2010-2011) and midline (2012-2013) surveys in 30 districts in India

\begin{tabular}{|c|c|c|c|c|c|c|c|}
\hline \multirow[t]{2}{*}{ Key knowledge's on TB } & \multicolumn{2}{|c|}{ Baseline $(n=3822)$} & \multicolumn{2}{|c|}{ Midline $(n=4211)$} & \multicolumn{2}{|l|}{ Total } & \multirow[t]{2}{*}{${ }^{* * *} p$-value } \\
\hline & $n$ & $\%$ & $n$ & $\%$ & $n$ & $\%$ & \\
\hline \multicolumn{8}{|l|}{ Symptoms* } \\
\hline Cough of $\geq 2$ weeks & 2829 & 74 & 3421 & 81 & 6250 & 78 & $<0.001$ \\
\hline Chest pain & 1147 & 30 & 1138 & 27 & 2285 & 28 & 0.112 \\
\hline Coughing blood & 1721 & 45 & 2311 & 55 & 4032 & 50 & $<0.001$ \\
\hline Fever & 1262 & 33 & 1514 & 36 & 2776 & 35 & 0.090 \\
\hline Night sweat & 77 & 2 & 322 & 8 & 399 & 5 & 0.060 \\
\hline Weight loss & 650 & 17 & 1075 & 26 & 1725 & 21 & $<0.001$ \\
\hline Loss of appetite & 345 & 9 & 679 & 16 & 1024 & 13 & 0.002 \\
\hline Don't know & 421 & 11 & 282 & 7 & 703 & 9 & 0.070 \\
\hline \multicolumn{8}{|l|}{ Mode of transmission* } \\
\hline Air & 2293 & 60 & 2973 & 71 & 5266 & 66 & $<0.001$ \\
\hline Sharing of food & 1184 & 31 & 1568 & 37 & 2752 & 34 & $<0.001$ \\
\hline Sharing bed clothes & 535 & 14 & 875 & 21 & 1410 & 18 & 0.005 \\
\hline Hand shake & 688 & 18 & 394 & 9 & 1082 & 13 & $<0.001$ \\
\hline Don't know & 764 & 20 & 580 & 14 & 1344 & 17 & 0.004 \\
\hline \multicolumn{8}{|l|}{ Diagnosis* } \\
\hline Sputum & 2523 & 66 & 2764 & 66 & 5287 & 66 & 1.000 \\
\hline Chest X-ray & 2332 & 61 & 2281 & 54 & 4613 & 57 & $<0.001$ \\
\hline Other (blood, skin, urine) & 382 & 10 & 59 & 1 & 441 & 5 & 0.020 \\
\hline Don't know & 573 & 15 & 582 & 13 & 1155 & 14 & 0.100 \\
\hline \multicolumn{8}{|l|}{ Curability } \\
\hline Yes completely & 3364 & 88 & 3505 & 83 & 6869 & 85 & $<0.001$ \\
\hline Yes partially & 305 & 8 & 450 & 11 & 755 & 9 & 0.170 \\
\hline No & 38 & 1 & 51 & 1 & 89 & 1 & 1.000 \\
\hline Don't know & 115 & 3 & 205 & 5 & 320 & 4 & 0.390 \\
\hline \multicolumn{8}{|l|}{ Duration of treatment } \\
\hline 4 wks or less & 115 & 3 & 97 & 2 & 212 & 3 & 0.640 \\
\hline $1-5 \mathrm{mths}$ & 612 & 16 & 358 & 9 & 970 & 12 & 0.002 \\
\hline $6-8 \mathrm{mths}$ & 1759 & 46 & 2028 & 48 & 3787 & 47 & 0.220 \\
\hline$>8$ mths & 306 & 8 & 777 & 18 & 1083 & 13 & $<0.001$ \\
\hline Don't know & 1030 & 27 & 951 & 23 & 1981 & 25 & 0.124 \\
\hline Knows DOTS & 1059 & 28 & 1094 & 26 & 2153 & 27 & 0.043 \\
\hline${ }^{* *}$ Knows DOTS is free & 847 & 80 & 957 & 87 & 1804 & 22 & $<0.001$ \\
\hline${ }^{* * * * H e a r d}$ of TB & 3822 & 84 & 4211 & 88 & 8033 & 100 & $<0.001$ \\
\hline
\end{tabular}

*Multiple response, ${ }^{* *}$ Among those who knew DOTs, ${ }^{* * *}$ Chi-square test for comparison of proportions, ${ }^{* * * *}$ Respondents for baseline and midline are 4652 and 4804 respectively. Project is raising awareness on drug sensitive as well as drug resistant tuberculosis and the treatment duration are $6-8$ months and $>8$ months are considered correct

could be attributed to the community level interventions though this requires more evidence to establish association.

Knowledge about chest pain as symptoms, TB is completely curable, and DOTS did not change much which requires focused messages during the ongoing interventions. The misconception on the diagnostic tests "chest X-ray, blood examination and skin test" was reduced but the misconception that TB spreads "through sharing food and clothes" still persists, also needs additional attention. Small scale studies published from India have shown that the awareness of TB (94\%), and knowledge on cough $(73 \%, 82 \%)$, mode of transmission (65\%, $81 \%)$, sputum test (40\%), and duration of treatment $(6.9 \%)$ have varied in different settings and population 
Table 3 Mean score of TB Knowledge by selected respondent's sociodemographic characteristics in baseline (2010-2011) and midline (2012-2013) surveys in 30 districts of India

\begin{tabular}{|c|c|c|c|c|}
\hline \multirow[t]{2}{*}{ Characteristics } & & \multicolumn{3}{|c|}{ Mean TB knowledge } \\
\hline & & Baseline survey* & & Midline survey* \\
\hline \multicolumn{5}{|l|}{ Sex } \\
\hline Female & 1806 & 5 & 2068 & 5.5 \\
\hline Male & 2016 & 5.36 & 2143 & 5.8 \\
\hline \multicolumn{5}{|l|}{ Age (years) } \\
\hline $18-24$ & 609 & 5.32 & 629 & 5.6 \\
\hline $25-34$ & 1057 & 5.08 & 1134 & 5.7 \\
\hline $35-44$ & 1209 & 5.09 & 1068 & 5.6 \\
\hline $45-54$ & 787 & 5.21 & 748 & 5.2 \\
\hline$>55$ & 160 & 5.34 & 632 & 5.6 \\
\hline \multicolumn{5}{|l|}{ Settlement } \\
\hline Rural & 2759 & 4.85 & 2915 & 5.5 \\
\hline Urban & 1063 & 6.12 & 1296 & 6.0 \\
\hline \multicolumn{5}{|l|}{ Education } \\
\hline Illiterate & 989 & 4.32 & 889 & 5.4 \\
\hline literate & 2833 & 5.53 & 3296 & 5.8 \\
\hline \multicolumn{5}{|l|}{ Income } \\
\hline$<4000$ & 2291 & 4.89 & 528 & 5.4 \\
\hline$>4001$ & 1531 & 5.64 & 3683 & 5.8 \\
\hline \multicolumn{5}{|l|}{ Zones } \\
\hline North & 1020 & 3.5 & 990 & 5.6 \\
\hline East & 1050 & 3.6 & 1182 & 5.5 \\
\hline West & 979 & 3.9 & 1130 & 6.0 \\
\hline South & 773 & 3.6 & 909 & 5.1 \\
\hline
\end{tabular}

*All $p$-value within groups (ANOVA) is $<0.001$. Range in baseline survey; $0-11$; Range in midline survey, 0-13 studied [15-17]. Unlike those studies, these serial surveys have shown that the level of awareness and knowledge on TB has increased over 2 years of community level interventions.

Most common source of TB related information was television and healthcare providers in baseline which changed to Interpersonal Communication (IPC) followed by television in the midline. Television was the preferred source of information for TB in midline which reflects the potential of mass media strategies to educate the community. The television users among the respondents increased from $59 \%$ in baseline to $77 \%$ in the midline which might have indirectly influenced the increase source of information as television but this needs additional investigation. In a similar setting in Bangladesh, massmedia intervention by government and Bangladesh Rural Advancement Committee (known as BRAC) found to have increased awareness at community level [18]. IPC as the commonest source of information in the midline could be due to the project interventions like, community meetings and house-to-house visits by community volunteers and sensitization of community health care providers who are the first point of contact to almost half of the population in the intervention districts $[11,13,14]$. IPC as preferred source of TB related information has been described as an effective strategy and has resulted to increase visits to NTP services [19]. This justifies the importance of strategizing communication channels like IPC among vulnerable and marginalized communities. Multiple logistic regression analysis was performed to determine the association of respondent's sociocharacteristics on the outcome measures (correct knowledge). There were significant difference in age, settlement, education and income of respondents between two survey. In both survey, the respondents were selected taking into

Table 4 Source and preferred sources of tuberculosis related information among general population in baseline (2010-11) and midline (2012-13) surveys in 30 districts in India

\begin{tabular}{|c|c|c|c|c|c|c|c|}
\hline \multirow[t]{2}{*}{ Variable } & \multicolumn{2}{|c|}{ Baseline $(n=4652)$} & \multicolumn{2}{|c|}{ Midline $(n=4804)$} & \multicolumn{2}{|c|}{ Total $(n=9456)$} & \multirow[t]{2}{*}{$p$-value } \\
\hline & $n$ & $\%$ & $n$ & $\%$ & $n$ & $\%$ & \\
\hline \multicolumn{8}{|l|}{ Source of TB related information } \\
\hline Television & 1675 & 37 & 2697 & 56 & 4372 & 47 & $<0.001$ \\
\hline Hospital doctors & 1665 & 37 & 2055 & 43 & 3720 & 40 & $<0.001$ \\
\hline Newspaper/magazine/hoarding/posters & 1416 & 31 & 1730 & 36 & 3146 & 34 & 0.003 \\
\hline IPC & 1233 & 27 & 2799 & 58 & 4032 & 43 & $<0.001$ \\
\hline Radio & 944 & 11 & 584 & 12 & 1528 & 16 & 0.54 \\
\hline \multicolumn{8}{|l|}{ Source of preferred TB related information } \\
\hline Television & 2007 & 44 & 2942 & 61 & 4949 & 53 & $<0.001$ \\
\hline Hospital doctors & 2185 & 48 & 2565 & 53 & 4750 & 51 & $<0.001$ \\
\hline News paper/magazine & 1457 & 31 & 1176 & 24 & 2633 & 28 & $<0.001$ \\
\hline IPC & 2315 & 51 & 2916 & 60 & 5231 & 56 & $<0.001$ \\
\hline
\end{tabular}

IPC Interpersonal Communication, *Chi-square test for comparison of proportion 
Table 5 Univaraite and Multivariate logistic regression analysis of tuberculosis knowledge by selected respondent's sociodemographic characteristics in baseline (2010-2011) and midline (2012-2013) surveys in 30 districts of India

\begin{tabular}{|c|c|c|c|c|c|c|}
\hline \multirow[t]{2}{*}{ Characteristics } & \multirow{2}{*}{$\begin{array}{l}\text { Number (\%) with } \\
\text { good TB knowledge }\end{array}$} & \multicolumn{2}{|l|}{ Baseline survey } & \multirow{2}{*}{$\begin{array}{l}\text { Number (\%) with } \\
\text { good TB knowledge }\end{array}$} & \multicolumn{2}{|l|}{ Midline survey } \\
\hline & & OR $(95 \%$ Cl) $¥$ & OR $(95 \% \mathrm{Cl}) €$ & & OR (95 \% CI) $¥$ & OR $(95 \% \mathrm{Cl}) €$ \\
\hline \multicolumn{7}{|l|}{ Sex } \\
\hline Female & $472(26)$ & $0.8(0.7-0.9)^{*}$ & $0.8(0.7-0.9)^{*}$ & $624(30)$ & $1.3(1.1-1.5)^{*}$ & $0.7(0.6-0.9)^{*}$ \\
\hline Male & $632(31)$ & 1.0 & 1.0 & 783 (37) & 1.0 & 1.0 \\
\hline \multicolumn{7}{|l|}{ Age (years) } \\
\hline $18-24$ & $203(33)$ & 1.0 & - & $629(32)$ & 1.0 & 1.0 \\
\hline $25-34$ & $336(32)$ & $0.9(0.7-1.1)$ & - & $419(37)$ & $1.3(1.0-1.5)^{*}$ & $1.3(1.1-1.6)^{*}$ \\
\hline $35-44$ & $319(26)$ & $0.7(0.6-0.9)$ & - & $380(36)$ & $1.2(0.9-1.4)$ & $1.4(1.1-1.7)^{*}$ \\
\hline $45-54$ & $205(26)$ & $0.7(0.5-0.9)$ & - & $237(32)$ & $0.9(0.7-1.2)$ & $1.1(0.8-1.4)$ \\
\hline$>55$ & $41(26)$ & $0.8(0.5-1.3)$ & - & $171(27)$ & $0.7(0.6-1.0)$ & $0.9(0.7-1.2)$ \\
\hline \multicolumn{7}{|l|}{ Settlement } \\
\hline Rural & $618(22)$ & $0.4(0.4-0.5)^{*}$ & $0.4(0.4-0.5)^{*}$ & 891 (31) & $1.5(1.3-1.7)^{*}$ & $0.8(0.7-0.9)$ \\
\hline Urban & $486(46)$ & 1.0 & 1.0 & $516(40)$ & 1.0 & 1.0 \\
\hline \multicolumn{7}{|l|}{ Education } \\
\hline Illiterate & $159(16)$ & $0.5(0.4-0.6)^{*}$ & $0.5(0.3-0.4)^{*}$ & $167(19)$ & $2.5(2.1-3.0)^{*}$ & $0.5(0.3-0.6)^{*}$ \\
\hline literate & $945(33)$ & 1.0 & 1.0 & 1225 (37) & 1.0 & 1.0 \\
\hline \multicolumn{7}{|l|}{ Income } \\
\hline$<4000$ & $537(23)$ & $0.6(0.5-0.8)^{*}$ & $0.7(0.5-0.8)^{*}$ & $529(29)$ & $1.3(1.2-1.5)^{*}$ & $0.7(0.6-0.9)^{*}$ \\
\hline$>4001$ & $567(37)$ & 1.0 & 1.0 & 878 (36) & 1.0 & 1.0 \\
\hline \multicolumn{7}{|l|}{ Zones } \\
\hline North & $191(19)$ & $1.1(0.8-1.3)$ & $1.1(0.8-1.4)$ & $315(32)$ & $1.5(1.2-2.8)^{*}$ & $2.2(1.7-2.6)^{*}$ \\
\hline East & $373(36)$ & $2.3(1.9-3.0)^{*}$ & $2.0(0.9-3.0)^{*}$ & $374(32)$ & $1.5(1.2-1.8)^{*}$ & $2.1(1.6-2.5)^{*}$ \\
\hline West & $380(39)$ & $2.3(1.8-2.9)^{*}$ & $2.3(2.2-3.2)^{*}$ & $507(45)$ & $2.6(2.2-3.2)^{*}$ & $3.4(2.7-4.1)^{*}$ \\
\hline South & $160(21)$ & 1.0 & & $211(23)$ & 1 & 1.0 \\
\hline
\end{tabular}

OR odds ratio, Note: *OR, Odds of having good tuberculosis knowledge of respondents relative to the reference group with an OR of 1.0 ; $¥$, Univariate logistic regression analysis; $€$, Multivariate logistic regression analysis; In baseline, all demographic variables were significant $(p$-value $<0.05)$ except for age in Univariate logistic regression analysis and were included multiple logistic regression model; In midline, all variables were significant in Univariate logistic regression analysis and were included in logistic regression analysis; Income is per month; Income is in Indian Rupees (1US\$ = Rs.62)

consideration the sex (1:1) and geographic region (eastern, northern, western and southern). However the age, settlement, education, and income were not among the selection criteria. This could be the reason for differences. In both surveys, the association of correct knowledge was seen with individuals residing in eastern and western zones. The association was significant for north in the midline survey and also for the older age groups (25-34, 35-44 years).Contradicting to our findings, older age groups ( $>30$ years) were less likely to have high knowledge than young in a community in Ethiopia [20]. The respondents in East had good TB knowledge in baseline survey and the association did not increase in midline. Other projects and ongoing effort of NTP might also have contributed to this increase in knowledge.

The survey showed that women did not have good TB knowledge as compared to men. In midline this was more remarkable. Also coverage in all areas of knowledge among women was less than $50 \%$ in both surveys.
This could be partly due to a men dominated society in India where women hesitate to interact with strangers or even community health care workers. Gender inequality in health (including TB) is a major issue in India and gender sensitive communications interventions are to be planned within the project [21]. Illiterates were less likely to have good TB knowledge and need to develop strategies to increase awareness. Similar to the finding in our study, women and illiterates were less likely to have high TB knowledge in a survey in Ethiopia [20]. IPC is a preferred source of TB related information among the participants and this strategy could be effectively used to increase TB knowledge in the women and illiterates.

Despite increase in TB knowledge in the midline, there are numerous bottlenecks in implementation which includes wide and diverse geographical coverage, transportation inequalities, semantic barrier, socio cultural inequalities, standardization of messages, nonuniform communication channels, and varied capacity 
of NGOs, CBOs and community volunteers, and nonuniform NTP services. There are some limitations in this study: (i) the study represents 374 project districts and the data presented here cannot be generalized for the entire nation, (ii) the participants in the two surveys were different, (iii) the study is powered at the zonal level, and (iv) increase in TB knowledge could also be due to other intervention and projects, NTP efforts and due to increase in education and economic level of the respondents interviewed at midline. Further research is needed to understand cause effect relationship in the project with increase in knowledge and changes in $\mathrm{TB}$ services seeking behaviour, presumptive TB patient examination and TB patient diagnosed in NTP disaggregated by age, gender and socio-economic factors.

\section{Conclusion}

The knowledge of TB among general population in midline survey considerably increased than baseline however misconception on the mode of transmission and diagnosis still prevailed which needs to be strengthened through interpersonal communication. Correct knowledge was associated with, males, older age group, high income, literacy and individuals residing in north, east and west. Community level interventions for $\mathrm{TB}$ prevention and care in India, have possibly contributed to the increased TB knowledge which could be replicated in other high burden countries.

\section{Abbreviations \\ CBO: Community Based Organization; CV: Community volunteer; DOTS: Directly observed treatment short course; IPC: Interpersonal communication; KAP: Knowledge Attitude Practice; NGO: Non-government organization; NTP: National Tuberculosis Programme; TB: Tuberculosis}

\section{Acknowledgement}

We would like to take this opportunity to acknowledge the GfK MODE's research team, and Dr Karuna Sagili, Research Associate at The Union South East Asia Office.

\section{Funding}

The two serial surveys are part of the Axshya Project which is supported by The Global Fund to Fight against AIDS, TB and Malaria.

\section{Availability of data and materials}

The baseline and midline reports are publically available on Project Axshya website.

\section{Authors' contributions}

The following concept, analysis was led by BT and BMP. Subsequent review and contributions were made by SSC and JT. Final manuscript was read and approved by all authors.

\section{Competing interests}

The authors declare that they have no competing interests.

\section{Consent for publication}

Not applicable.

\section{Ethics approval and consent to participate}

The Ethics Advisory Group of the International Union Against Tuberculosis and Lung Disease (The Union), Paris, France, approved the study. Local ethics approval was obtained from the independent ethics committee of Resource Group for Education and Advocacy for community Health (REACH), Chennai,
India. The participants in the study were briefed about the purpose and the information being collected. Following this participants who gave consent (in writing) were included in the study. Right Hand thumb impression was used on the consent form in case of illiterate participant.

Received: 26 April 2016 Accepted: 28 October 2016

Published online: 11 November 2016

\section{References}

1. WHO. Tuberculosis control in South-East Asia Region. Annual Report 2015 New Delhi:2015. http://www.searo.who.int/tb/annual-tb-report-2015.pdf. Accessed 10 Dec 2015

2. WHO. Global Tuberculosis Report 2012. Geneva: 2013. http://apps.who.int/iris/ bitstream/10665/75938/1/9789241564502_eng.pdf. Accessed 10 Dec 2015

3. Thapa B, Chadha SS, Das A, Mohanty S, Tonsing J. High and equitable tuberculosis awareness coverage in the community-driven Axshya TB control project in India. Public Health Action. 2015;5(1):70-3.

4. Sudha G, Nirupa C, Rajasakthivel M, Sivasusbramanian S, Sundaram V, Bhatt S, et al. Factors influencing the care-seeking behaviour of chestsymptomatics: a community-based study involving rural and urban population in Tamil Nadu, South India. Trop Med Int Health. 2003;8(4):336-41.

5. Satyanarayana S, Nair SA, Chadha SS, Shivashankar R, Sharma G, Yadav S, et al. From where are tuberculosis patients accessing treatment in India? Results from a cross-sectional community based survey of 30 districts. PLoS One. 2011;6:9.

6. Mushtaq M, Majrooh M, Ahmad W, Rizwan M, Luqman M, Aslam M, et al. KAP regarding tuberculosis. Int J Tuberc Lung Dis. 2010;14(3):303-10.

7. Balasubramanian R, Garg R, Santha T, Gopi P, Subramani R, Chandrasekaran $V$, et al. Gender disparities in tuberculosis: report from a rural DOTS programme in south India. Int J Tuberc Lung Dis. 2004;8(3):323-32.

8. Sachdeva KS, Kumar A, Dewan P, Kumar A, Satyanarayana S. New Vision for Revised National Tuberculosis Control Programme (RNTCP): universal access - "Reaching the un-reached". Indian J Med Res. 2012;135(5):690-4.

9. Union T. The International Union Against Tuberculosis and Lung Diseases. [Online]. New Delhi; 2011 [cited 2015 February. Available from: http://axshyatheunion.org/kap-study-report/. Accessed 10 Dec 2015

10. Union T. The International Union Against Tuberculosis and Lung Diseases. [Online].; 2014 [cited 2015 February. Available from: http://axshya-theunion. org/kap-study-report/. Accessed 10 Dec 2015

11. Union T. Project Axshya activity report 2012-13. Annual. New Delhi: The International Union Against Tuberculosis and Lung Disease, Tuberculosis; 2013.

12. Prasad BM, Satyanarayana S, Chadha SS, Das A, Thapa B, Mohanty S, et al. Expereince of active tuberculosis case finding 5 million households in India. Public Health Action. 2016;6(1):15-18.

13. Gol. TB India 2012. New Delhi: Directorate General of Health Services, Central TB Division; 2012. http://tbcindia.nic.in/showfile.php?lid=3141 Accessed 15 Jan 2016

14. Gol. TB India 2014. New Delhi: Directorate General of Health Services, Central TB Division; 2014..http://tbcindia.nic.in/showfile.php?lid=3142 Accessed 15 Jan 2016

15. Chinnakali P, Ramakrishnan J, Vasudevan K, Gurumurthy J, Upadhyay RP, Panigrahi KC. Level of awareness about tuberculosis in urban slums: implications for advocacy and communication strategy planning in the National program. Lung India. 2013;30(2):139-42.

16. Malhotra R, Taneja DK, Dhingra VK, Rajpal S, Mehra M. Awarenss regarding tuberculosis in a rural popilation of Delhi. Indian Community Med. 2002;27(2):62-8.

17. Yadav SP, Mathur ML, Dixit AK. Knowledge and attitude towards tuberculosis among sandstone quarry workers in desert parts of Rajasthan. Indian J Tuberc. 2006;53:187-95.

18. Paul S, Akter R, Aftab A, Khan AM, Barua M, Islam S, et al. Knowledge and attitute of key community members towards tuberculosis:mixed method study from BRAC TB control areas in Bangladesh. BMC Public Health. 2015;15:52.

19. Sharma N, Nath A, Davender KT, Gopal Kl. A qualitative evaluation of the information education and communication component of the tuberculosis control program in Delhi, India. Asia Pac J Public Health. 2009;21:321-32.

20. Tolossa D, Medhin G, Legesse M. Community knowledge, attitude and practices towards tuberculosis in Shinile town, Somali regional state, eastern Ethiopia: a cross-sectional study. BMC Public Health. 2014;14:804.

21. Raj A. Gender equity and universal health coverage in India. The Lancet. 2011;377(9766):618-9. 